\title{
Effects of a fish oil emulsion on plasma free fatty acids, cytokines, and clinical outcomes in septic patients: a randomized, controlled, clinical trial
}

\author{
V. M. Barbosa ${ }^{1}$, E. Lafuente ${ }^{2}$, C. Calhau ${ }^{3}$, E. A. Miles ${ }^{1}$ and P. C. Calder ${ }^{1}$ \\ ${ }^{1}$ Institute of Human Nutrition, University of Southampton, Southampton SO16, ${ }^{2}$ Unidade de Cuidados Intensivos, Hospital \\ Padre Américo EPE, Penafiel, Portugal and ${ }^{3}$ Departamento de Bioquímica, Faculdade de Medicina, Universidade do \\ Porto, Porto, Portugal
}

Inclusion of fish oil in parenteral nutrition (PN) may improve outcome in critically ill patients, but this has not been explored.

This study was designed to compare the effects of a conventional lipid emulsion with one containing fish oil on plasma phospholipid fatty acids, inflammatory markers and clinical outcomes in septic patients.

Twenty five consecutive patients admitted to an ICU with septic syndrome and predicted to require PN were studied. PN was administered for 5 days and included either a 50:50 MCT/LCT lipid emulsion (Nutriflex Lipid) or a 50:40:10 MCT/LCT/fish oil lipid emulsion (Lipoplus). Two patients were excluded, 13 received Lipoplus and 10 received Nutriflex Lipid. Blood was collected at admission, and on days 1 (before beginning infusion), 2 ( $24 \mathrm{~h}$ after starting infusion) and 6 ( 5 days after starting infusion).

Plasma phospholipid fatty acid composition was measured by gas chromatography. Plasma and endotoxin stimulated cytokines and eicosanoids were measured by ELISA. Clinical outcomes were monitored.

The proportion of EPA in plasma phospholipids increased in the fish oil group and was significantly higher at day 6 than in the MCT/LCT group $(P<0.001)$.

Plasma IL-6, IL-1 $\beta$ and TNF- $\alpha$ were high on admission and declined thereafter in both groups. There was no significant effect of the type of lipid emulsion on plasma or LPS-stimulated cytokines or eicosanóides. There was considerable heterogeneity in these measures.

Gas exchange improved in the fish oil group. At day $6, \mathrm{PCO}_{2}$ and the ratio $\mathrm{PO}_{2} / \mathrm{FiO}_{2}$ were significantly higher in the fish oil group than in the MCT/LCT group (Table1).

Table 1. Gas exchange parameters in the two groups

\begin{tabular}{|c|c|c|c|c|c|c|c|c|}
\hline & \multicolumn{4}{|c|}{ Fish oil group } & \multicolumn{4}{|c|}{ MCT/LCT group } \\
\hline & Admission & Day 1 & Day 2 & Day 6 & $\overline{\text { Admission }}$ & Day 1 & Day 2 & Day 6 \\
\hline $\begin{array}{l}\mathrm{PCO}_{2}(\mathrm{~mm} \mathrm{Hg}) \\
\mathrm{PO}_{2} / \mathrm{FiO}_{2}\end{array}$ & $\begin{array}{r}78 \pm 125 \\
269 \pm 125\end{array}$ & $\begin{array}{c}39 \pm 7 \\
248 \pm 81\end{array}$ & $\begin{array}{c}41 \pm 6 \\
253 \pm 102\end{array}$ & $\begin{array}{c}48 \pm 8^{*} \\
331 \pm 71 * *\end{array}$ & $\begin{array}{c}36 \pm 8 \\
262 \pm 132\end{array}$ & $\begin{array}{c}39 \pm 10 \\
252 \pm 125\end{array}$ & $\begin{array}{c}40 \pm 8 \\
299 \pm 80\end{array}$ & $\begin{array}{c}40 \pm 8 \\
245 \pm 107\end{array}$ \\
\hline
\end{tabular}

$* P=0.033 v . \mathrm{MCT} / \mathrm{LCT}$ group. $* * P=0.040 v . \mathrm{MCT} / \mathrm{LCT}$ group.

Patient characteristics including disease severity were similar in both groups at admission. Length of hospital stay was significantly shorter in the group receiving fish oil $(22 \pm 7 v .55 \pm 16$ days; $P=0.05)$. There were no other differences in other clinical outcomes.

In conclusion, a lipid emulsion containing fish oil increases plasma EPA content and reduces length of hospital stay in recently admitted ICU patients with septic syndrome. 